Article

\title{
A 3D Printed Membrane-Based Gas Microflow Regulator for On-Chip Cell Culture
}

\author{
Agnieszka Podwin *, Rafał Walczak and Jan Dziuban \\ Faculty of Microsystems Electronics and Photonics, Wroclaw University of Science and Technology, \\ 50-370 Wrocław, Poland; rafal.walczak@pwr.edu.pl (R.W.); jan.dziuban@pwr.edu.pl (J.D.) \\ * Correspondence: agnieszka.podwin@pwr.edu.pl; Tel.: +71-320-4994
}

Received: 27 February 2018; Accepted: 3 April 2018; Published: 8 April 2018

\begin{abstract}
A miniature 3D printed membrane-based gas microflow regulator which delivers gaseous media to on-chip cell cultures is presented in this paper. The device uses a polydimethylosiloxane (PDMS) membrane to act as a diffusion barrier and maintain gas flow at the desired rate. The regulator was characterized, and repeatable flow values for different membrane thicknesses and gas types in the function of pressure were obtained. As a result, a long-term on-chip culture of Euglena gracilis was achieved, this was due to constant and stable carbon dioxide release from the regulator (flow rate: $0.3 \mu \mathrm{L} / \mathrm{min})$.
\end{abstract}

Keywords: gas microflow; gas regulation; PDMS membrane; 3D printing

\section{Introduction}

Precise control of flow rates and gaseous media volumes in microfluidic devices is a crucial issue in a variety of bio-based applications. Such regulation is especially important in the field of cell culturing, where high precision-flows of less than a few microliters per minute-has to be achieved [1-3]. For this purpose, mechanical micropumps, flow restriction reducers, or valves are often utilized [4-8]. However, such commercially available solutions are often not very portable and are also considered to be relatively expensive. Aside from the use of ready-to-use devices, a discernable tendency to fabricate self-contained microfluidic systems has recently appeared in the literature [9-11]. In these cases, in order to appropriately adjust and direct the average flow, the structures are usually equipped with embedded valves, separation microchannels, and/or diffusion barriers [12-16]. Ozasa et al. describe a simple polydimethylosiloxane (PDMS) lab-on-a-chip, in which the chemotaxis of microorganisms was investigated according to a selective supply of different gaseous media through the semi-permeable PDMS microchannels [17]. Cook et al. also propose a high-density cell culture system based on PDMS membranes, but enriched with parylene coatings, which protect the culture from the undesired leaching of uncured PDMS oligomers [18]. A novel approach to obtain a self-contained cell culturing microfluidic system was presented in reference [19]. The authors describe a hydrogel, the operation of which was greatly improved by the insertion of microgrooves and microchannels on its surface. Such a solution may significantly inhibit excessive rigidity of the hydrogel, decreasing rehydration of the 3D cell cultures on-chip.

It may be contended that in the literature there are plenty of self-contained microfluidic systems dedicated to cell culturing, whose performance has been thoroughly investigated and then successfully applied. Nevertheless, the main drawbacks of the aforementioned solutions are the complexity of the technology and their limited use. For this reason, and a change in the experimental demands, a new chip design has to be proposed.

On the basis of the advantages and shortcomings of the current solutions, in this work a small-scale, handheld, and easily configurable 3D printed membrane-based gas microflow regulator 
is proposed. The device may be applied to deliver gaseous media to polymer microfluidic systems, such as PDMS or glass lab-on-a-chips, as shown in this work. It is suitable to generate bubbles in the liquid medium, which, once nourished, are directed to the cell cultures-on-chip. The regulator controls the specified flow rate of the medium, before it is delivered to the lab-on-a-chip. The microfluidic system does not require improvements in its structure, since the flow adjustment is provided at the level of the regulator.

In this work, the device was used to deliver gaseous media to the microchannels of the all-glass lab-on-a-chip to achieve a long-term culture of Euglena gracilis.

The working principle of the regulator is based on the well-known phenomenon of gas permeation in thin membranes of silicon elastomers, i.e., PDMS [20,21]. The authors investigated PDMS in a recently published article [22], concerning a lab-on-a-chip bioreactor for the biochemical energy cascade of microorganisms. The knowledge acquired during the aforementioned study enabled us to propose a novel construction for the regulator, utilizing interesting features of PDMS, i.e., permeability. The permeability value $(P)$, in most of the applications, can be defined by the Formula (1) [23-25].

$$
P=\frac{v \times \delta}{A \times t \times\left(p_{1}-p_{0}\right)}
$$

where:

$v$ is the volume of gas penetrating the membrane,

$\delta$ is the membrane thickness,

$A$ is the surface area of the membrane,

$t$ is the time,

$p_{1}$ is the input pressure,

$p_{0}$ is the output pressure.

On the basis of the given Equation (1), the flow value may be derived (2), which, basically, depends solely on the pressure difference and parameters of the membrane, including its material type.

$$
\frac{v}{t}=\frac{P \times A \times\left(p_{1}-p_{0}\right)}{\delta}
$$

In our concept, the gaseous medium under pressure $p_{1}$ permeates through the membrane and reaches the lab-on-a-chip under pressure $p_{0}$, being approximately equal to the atmospheric pressure (Figure 1). The flow rate-for the fixed construction of the regulator-changes linearly with the pressure, the membrane surface, and its permeability, and is inversely proportional to the membrane thickness.

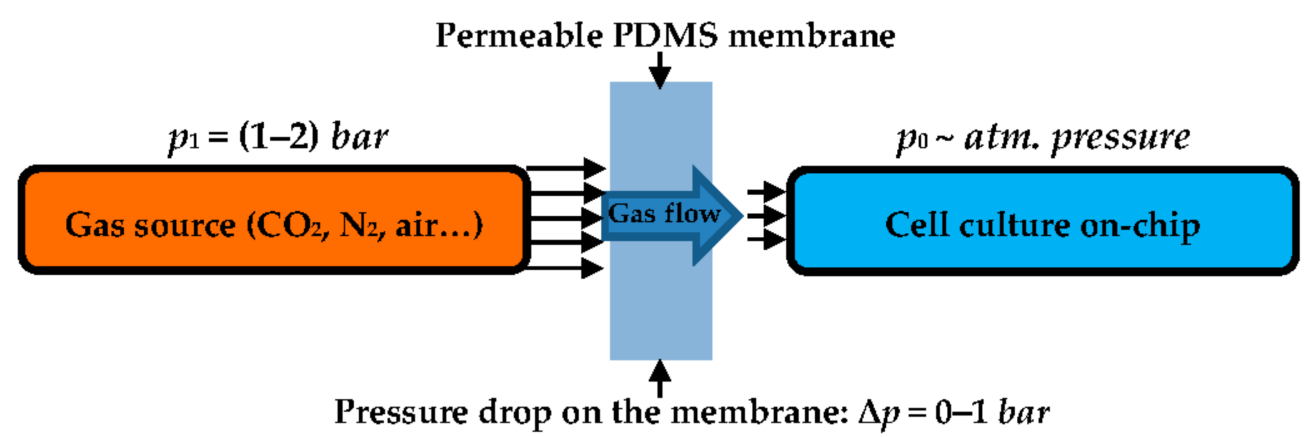

Figure 1. Concept of flow regulation in the 3D printed membrane-based gas microflow regulator. PDMS: polydimethylosiloxane. 


\section{Materials and Methods}

\subsection{Design and Fabrication of the Regulator}

Polydimethylosiloxane (PDMS) membranes were formed by molding. Liquid PDMS, (Sylgard 184, Dow Corning, Midland, MI, USA) mixed with its curing agent at a ratio of 10:1 (w/w) and degassed, was poured into an ink-jet 3D printed matrix (printer model: Projet 3510, 3D Systems, Rock Hill, SC, USA, photo-curable material: Visijet M3 Crystal) with defined cavities. The polymerization process was enhanced by heating the mold for $1 \mathrm{~h}$ at $70{ }^{\circ} \mathrm{C}$. As a result, 200, 300, and $400 \pm 5 \mu \mathrm{m}$ thick membranes, measured precisely by caliper (Mitutoyo, Japonia), were fabricated and tested.

Other functional elements of the regulator were also obtained utilizing ink-jet 3D printing techniques; rapid prototyping, simplicity of fabrication, and an increasing resolution are driving the growing popularity of its use in the bio-scientific fields [26,27]. The device contains: bottom part, pressing ring, aforementioned PDMS membrane, sieve, O-ring seal (not printed), top part, and microfluidic connector that joins the regulator with the lab-on-a-chip. The membrane is attached to the sieve by the pressing ring on the top part. The surface of the sieve is structured to properly stiffen the membrane and hold it in place. It is also perforated to enable the gaseous medium flow from the diaphragm. Because of this, the active surface of the membrane is minimized and is $12.5 \mathrm{~mm}^{2}$. The role of the sieve is important, since it prevents the membrane from any possible breakage during high-pressure measurements. It acts as a reinforcement and protects from any undesired membrane bulge and shape change. If the sieve is not utilized, the gas transport through the membrane is unstable and unrepeatable. The regulator is assembled using a threaded connection between the bottom and top part. Its outer dimensions are $35 \mathrm{~mm} \times 24 \mathrm{~mm}$ (Figure 2).

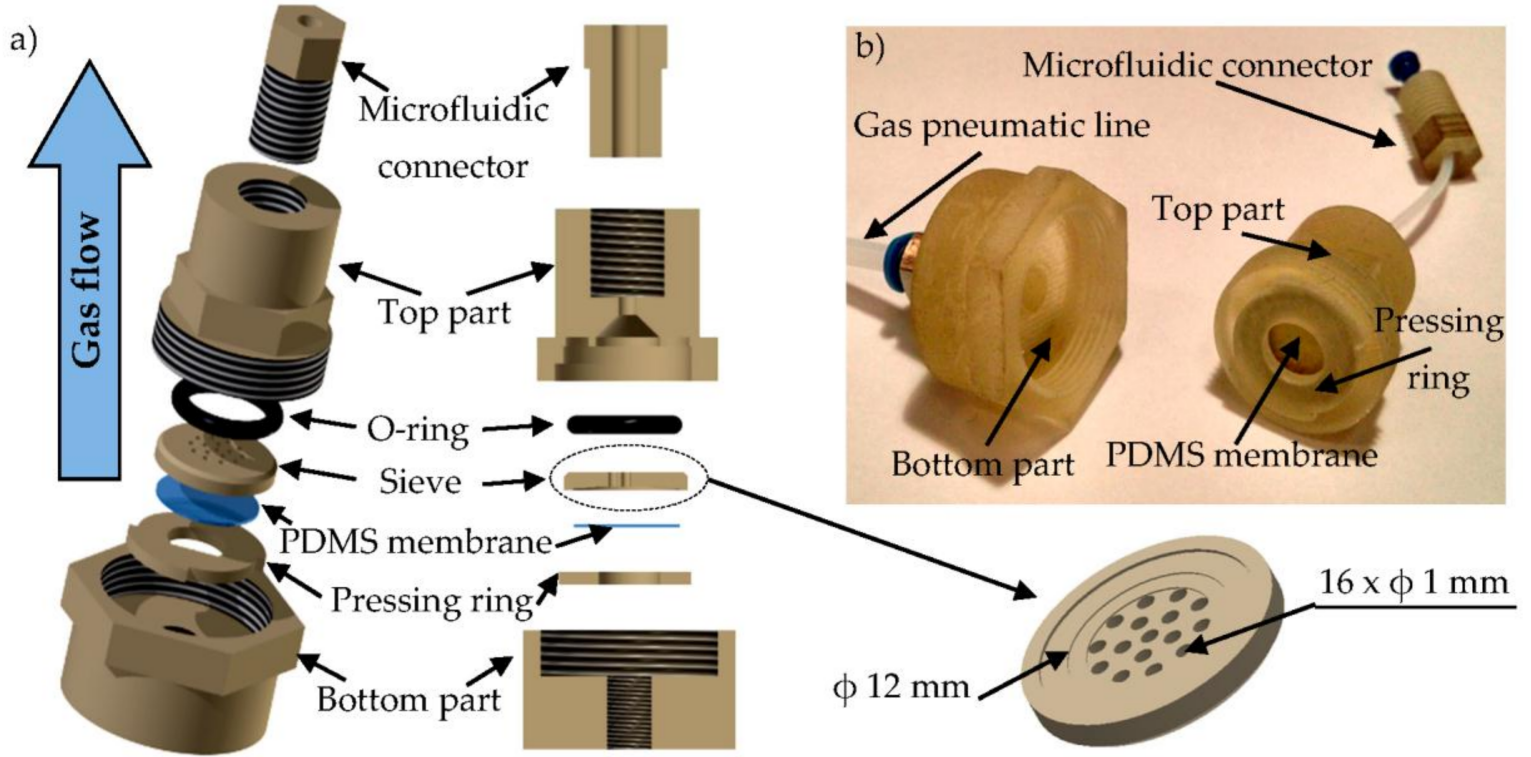

Figure 2. 3D printed membrane-based gas microflow regulator: (a) on the left, exploded schematic view; on the right, cross section with magnified view of the sieve; (b) bottom and top part of the regulator prior to assembly.

During the operation, the gaseous medium from the pneumatic line reaches the bottom part of the device and comes across the diffusion barrier (PDMS membrane). Depending on the membrane thickness, the flow rate is regulated and then directed to the lab-chip platform containing the cell culture through the microfluidic connector on the top part. 


\subsection{Flow Measurements and Microbial Culture-On-Chip Setups}

Gas sources of carbon dioxide (99.9\%), nitrogen (99.99\%), and air (99.99\%) (Air Products, Warsaw, Poland) were delivered to the regulator through the pneumatic line equipped with a valve (Bibus Menos, Gdańsk, Poland) and precise reducer (Shimadzu, Kyoto, Japan). The flow value was indicated using a bubble detection method. The quantity of bubbles per time unit and their volume was detected at the regulator output using a digital microscope with CCD sensor (model: 23713, Bresser, Rhede, Germany). On the basis of the recorded image sequence, the flow was defined. The view of the measurement setup is presented in the Figure 3.

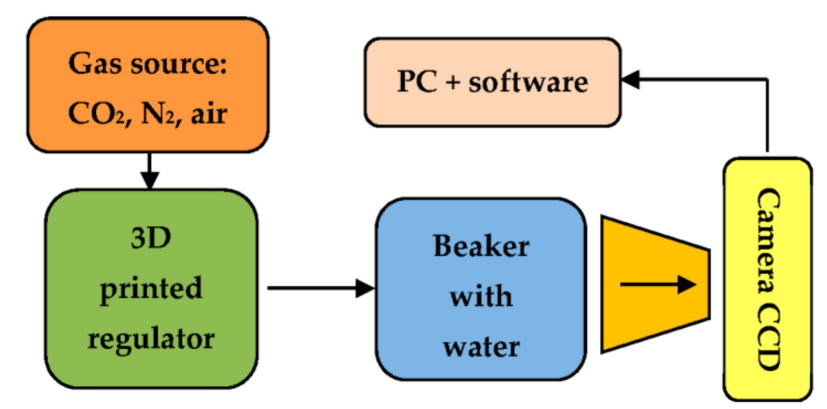

Figure 3. Measurement setup scheme for evaluation of flow values. PC: personal computer.

A macroscale culture of E. gracilis was purchased (Blades Biological Ltd., Edenbridge, UK) and maintained according to the guidelines (Blades Biological Ltd., Protozoa and algae culture instructions). The microorganisms were investigated in the glass lab-on-a-chip, the technology, structure, and properties of which are described elsewhere in detail [28]. An image of the E. gracilis culture was captured using an optical microscope (model: NJF-120A, Delta Optical, Mińsk Mazowiecki, Poland) with an integrated CCD camera and processed utilizing dedicated real-time tracking software $[29,30]$. In order to properly connect the regulator with the lab-on-a-chip, it was placed in a $3 \mathrm{D}$ printed holder.

The view of the lab-on-a-chip platform with the regulator is shown in the Figure 4 .

a)

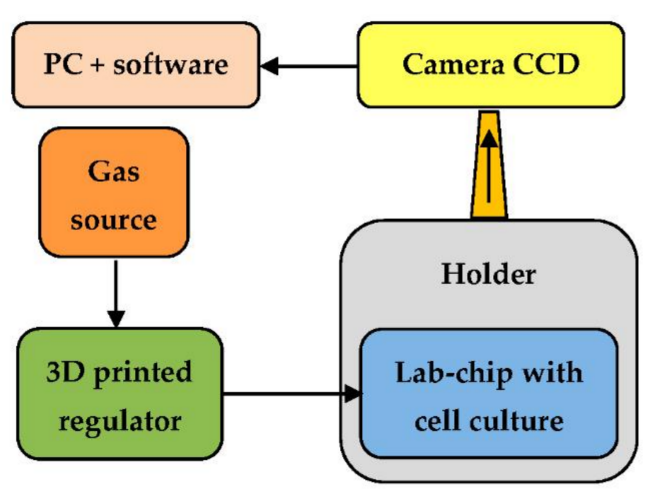

b)

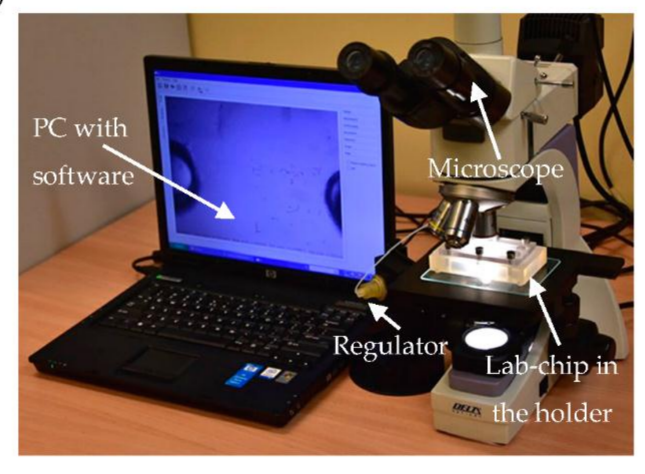

Figure 4. Measurement setup for on-chip cell culture: (a) scheme; (b) real view.

\section{Results and Discussion}

\subsection{Flow Characteristics of the Regulator}

Flow charts of the regulator were devised for three PDMS membrane thicknesses $(200,300$, $400 \pm 5 \mu \mathrm{m}$ ) and three types of gases (air, $\mathrm{CO}_{2}, \mathrm{~N}_{2}$ ), concerning increases and decreases in the operational pressure (Figures 5 and 6 ). The measurements were repeated three times for each set. 
The attached graphs represent the mean value from every configuration. In order to check the gas flow repeatability, the standard deviation within the particular measurement group is indicated. Its value ranges from $2.6 \%$ to $7.2 \%$ in the case of $\mathrm{CO}_{2}$ flow, $2.8-5.4 \%$ for $\mathrm{N}_{2}$, and $3.7-6 \%$ for air flow, according to the different membrane thicknesses.

a)

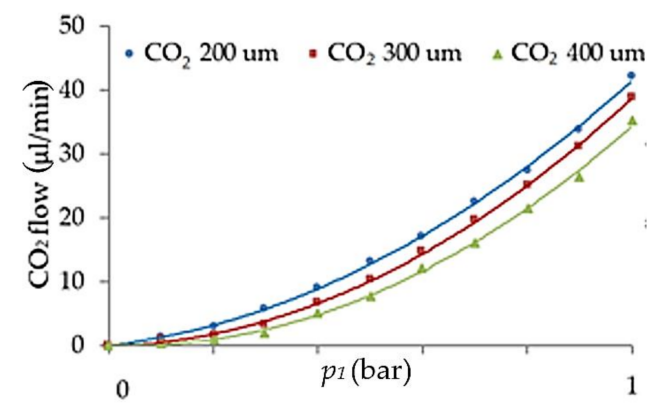

c)

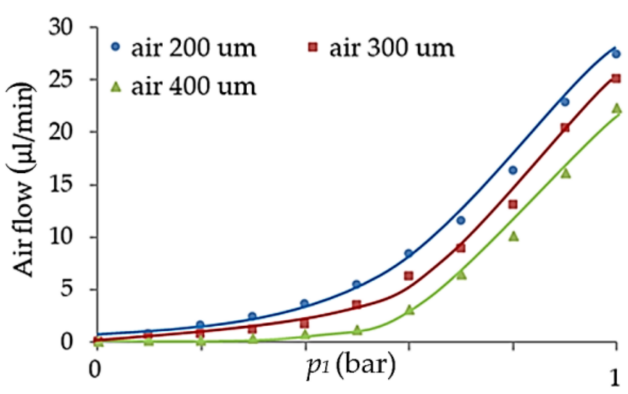

b)

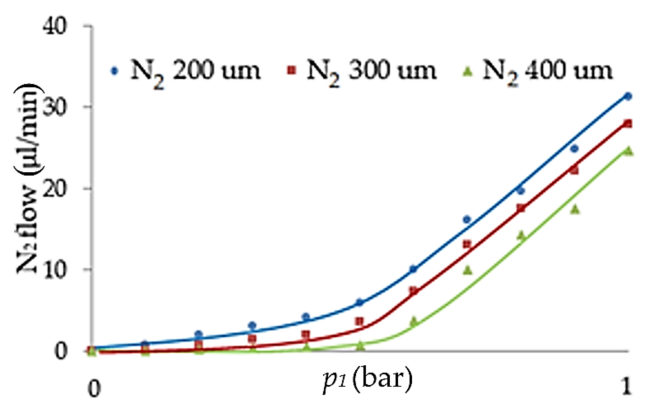

d)

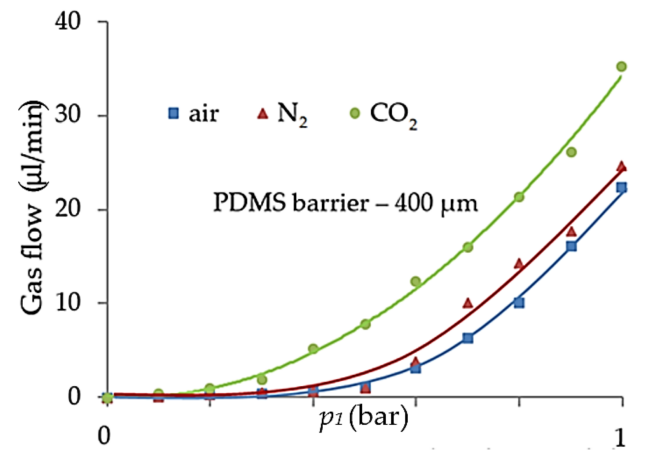

Figure 5. Gas flow characteristics of the regulator for different polydimethylosiloxane (PDMS) membrane thicknesses: (a) $\mathrm{CO}_{2}$ flow; (b) $\mathrm{N}_{2}$ flow; (c) air flow; (d) flow comparison for the selected gases with a $400 \mu \mathrm{m}$ thick PDMS membrane.

a)

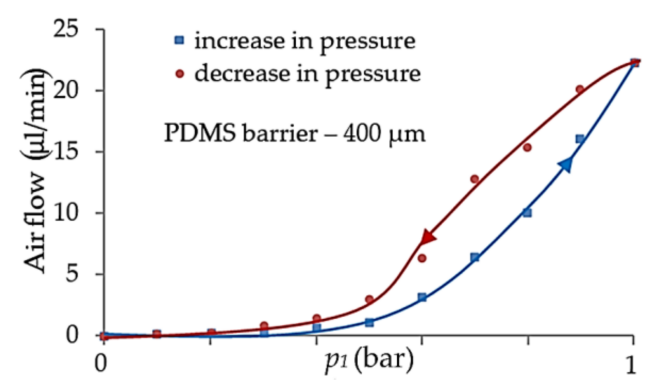

c)

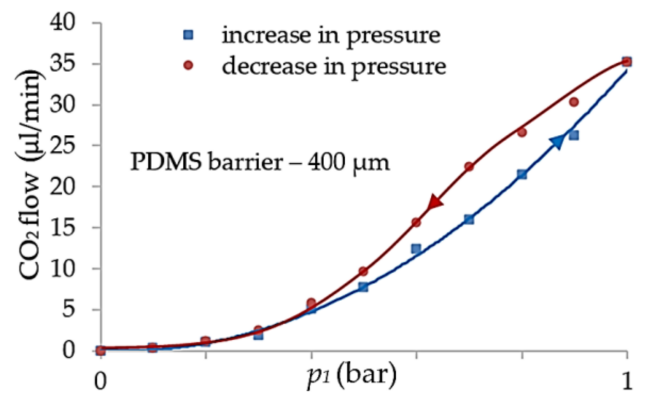

b)

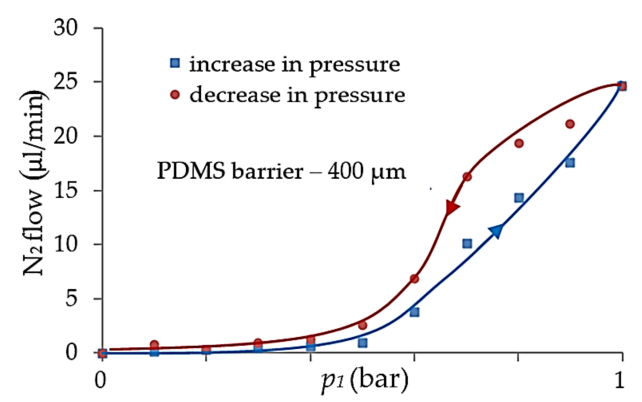

Figure 6. Pneumatic hysteresis of the regulator with a $400 \mu \mathrm{m}$ thick PDMS membrane: (a) air flow; (b) $\mathrm{N}_{2}$ flow; (c) $\mathrm{CO}_{2}$ flow. 
The statistical analysis showed that the flow changes parabolically with applied pressure, also depending on the membrane thickness. Diversities in the flow rate were also noticed depending on the type of gas. The shape of the characteristics (approximately parabolic) is consistent with the data found in the literature [31-33]. Obtained curves are, amongst other things, associated with an increasing solubility of gases as the pressure value increases. This phenomenon causes the growth of gas concentration, which slightly plasticizes the polymer bulk and increases permeability [31]. It is especially noticeable for organic penetrants, like $\mathrm{CO}_{2}$, and less for sorbing gases, such as $\mathrm{N}_{2}$ and $\mathrm{O}_{2}$. It justifies the characteristics presented in the Figure $4 \mathrm{~d}$, in which the flow value of $\mathrm{CO}_{2}$ increases the fastest with applied pressure. Another factor that points to a higher permeability is the molecule size; the flow value of $\mathrm{CO}_{2}$ in this case is the highest [33]. According to the formula (1) shown in the first section of the article, the flow ought to change linearly depending on the membrane thickness. In our case, the results depart from the linearity by circa $25 \%$. The reason why such diversities were observed may be related to the preparation and polymerization of the membranes. The membranes were obtained by manual mixing of the prepolymer. In this way, the crosslinking network of each membrane could have had some irregularities, i.e., smaller or greater pores that influenced the flow characteristics. The measurements also revealed that the regulator exhibited pneumatic hysteresis (Figure 6). This phenomenon may be related to the gathering of gas particles in the polymer bulk and their gradual release. This could be reduced or even avoided by waiting a short time for stabilization after changing the parameters of the pressure.

\subsection{Application of the Regulator for Culturing of E. Gracilis}

On the basis of the flow characteristics, the regulator was used to deliver carbon dioxide to the lab-on-a-chip containing E. gracilis. The authors decided to culture this species because $E$. gracilis is an interesting model microorganism [34]. It has recently been widely investigated in the field of microfluidics as a result of, amongst other things, the ease of obtaining it from the environment, as well as its high sensitivity to different external factors [17,35]. The mentioned sensitivity of E. gracilis may provide vital information on, for instance, the toxicology of freshwater environments, as indicated in [36].

In this study, the photosynthetic growth of these microorganisms was investigated in a two-week period with $\mathrm{CO}_{2}$ flow rate equal to $0.3 \mu \mathrm{L} / \mathrm{min}$ (the regulator with $400 \mu \mathrm{m}$ thick PDMS membrane, pressure equal to 0.1 bar, was applied, Figure 7). The construction of the regulator-tight with no gas leakage-provided an equal and stable flow rate during the measurements. As a result, a notable population growth of $E$. gracilis was observed through optical detection methods. Both the qualitative and quantitative analysis of the culture was conducted using real-time tracking software (Figure 8). The on-chip cell culture increased five times from beginning to end (Figure 9). Such a result indicates appropriate culturing conditions in the lab-on-a-chip chamber, enhanced by the $\mathrm{CO}_{2}$ microflow from the regulator.

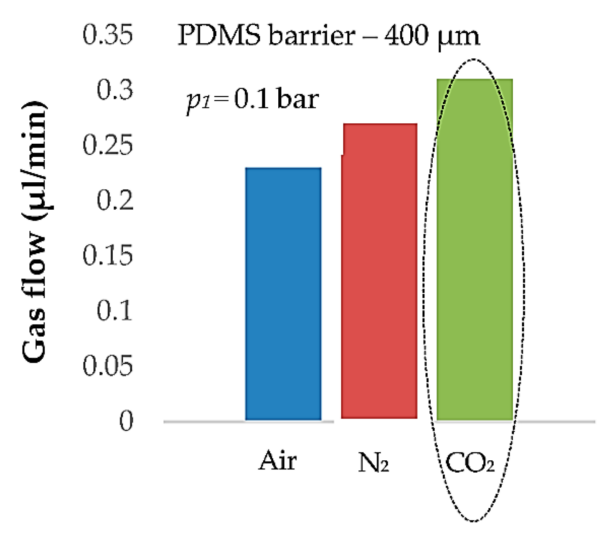

Figure 7. The comparison of flow values of the regulator for different gases but fixed input pressure and PDMS membrane. 
a)

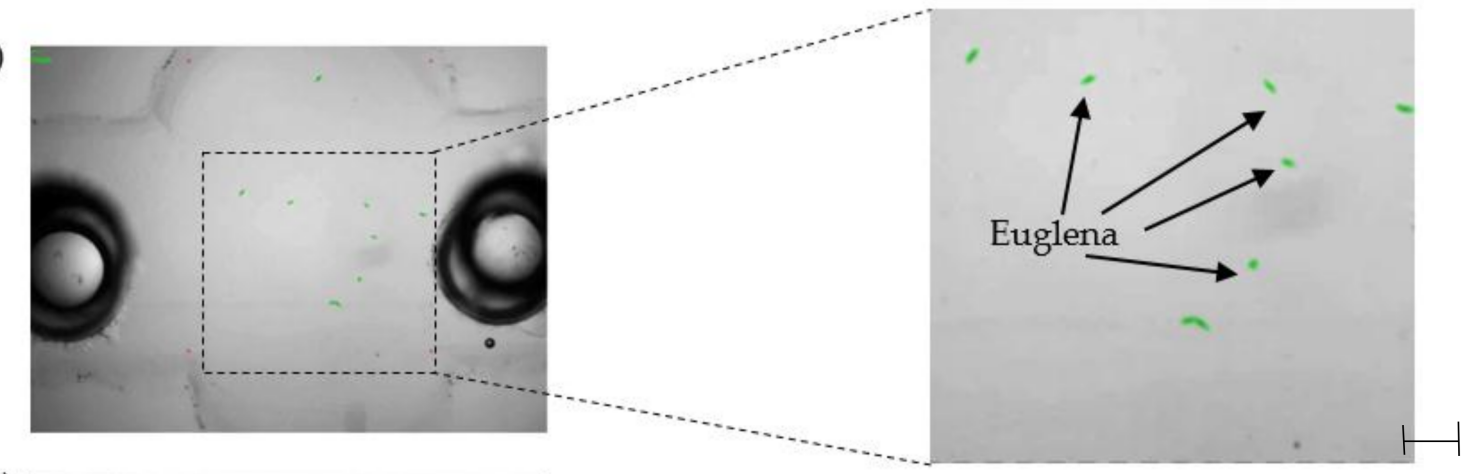

b)

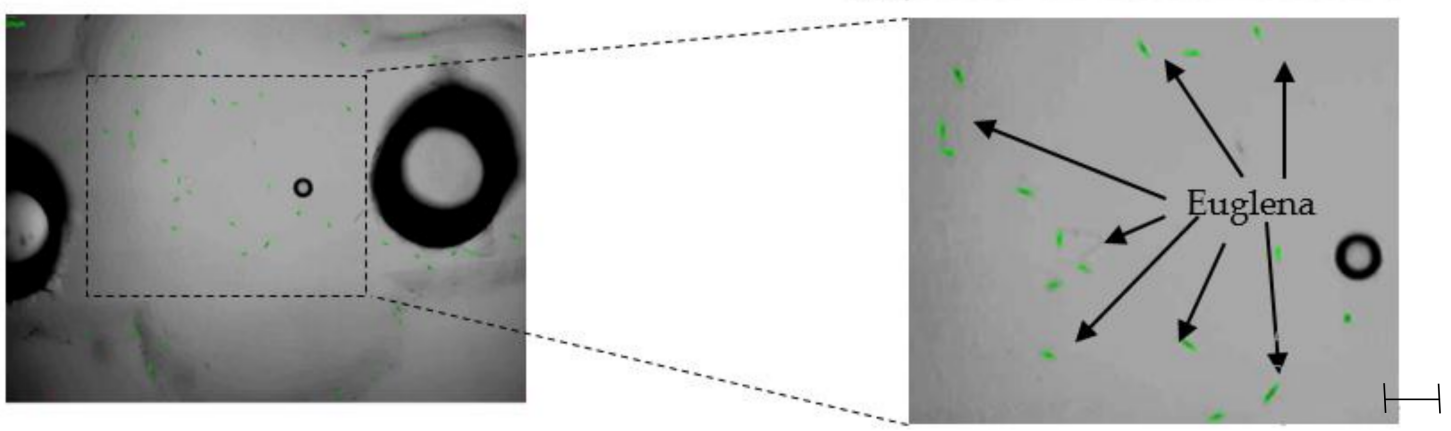

Figure 8. Growth of Euglena gracilis population on-chip ranging from 8 to 44 cells. E. gracilis colonies are marked as green dots by the software: (a) start of the test; (b) end of the test. Scale bar: $50 \mu \mathrm{m}$.

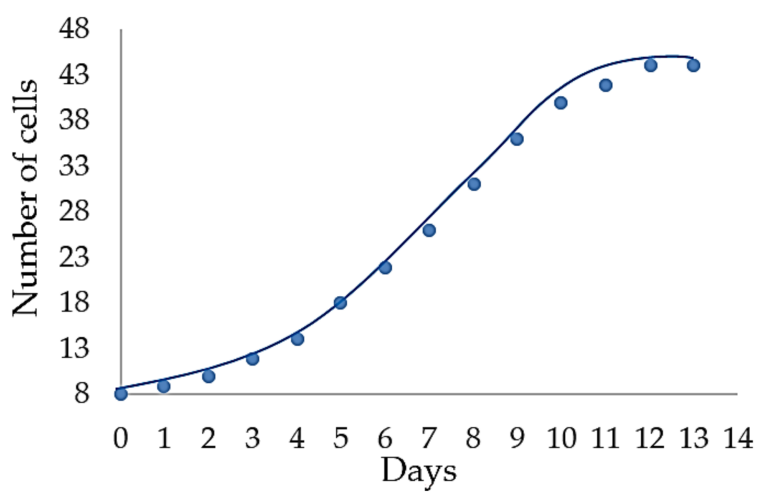

Figure 9. Characteristics of E. gracilis population growth on-chip: approximately parabolic dependence on time, consistent with the literature data [37].

\section{Conclusions}

In this paper, a 3D printed membrane-based gas microflow regulator is presented. The flow characteristics of the device for different PDMS membrane thicknesses, pressure values, and gas types were obtained. The application of the regulator for the maintenance of the on-chip cell culture is shown. The device was successfully utilized for a two-week culture of E. gracilis, using a precise and repeatable dosage of carbon dioxide to the lab-on-a-chip. The results of the experiments show that it is possible to regulate the gas flow at a desired rate and utilize the permeability of PDMS and 3D printing techniques to create a new tool for the rapid development of microfluidic structures.

Acknowledgments: I would like to acknowledge Krzysztof Adamski (Wroclaw University of Science and Technology, Poland) for the operation of the printer; I also would like to thank Danylo Lizanets (Wroclaw University of Science and Technology, Poland) for the image processing. The work was financed by the Statutory Grant for Young Scientists of Wroclaw University of Science and Technology number 0402/0052/17 and 
Polish National Science Centre (NCN) under the project number 2015/19/BST8/01110, in the part concerning image processing.

Author Contributions: A.P. performed the experiments, analyzed the data, and wrote the paper; R.W. developed the technique of 3D printing dedicated to microfluidics; J.D. conceived and designed the experiments.

Conflicts of Interest: The authors declare no conflict of interest.

\section{References}

1. Weltin, A.; Slotwinski, K.; Kieninger, J.; Moser, I.; Jobst, G.; Wego, M.; Ehret, R.; Urban, G.A. Cell culture monitoring for drug screening and cancer research: a transparent, microfluidic, multi-sensor microsystem. Lab Chip 2014, 14, 138-146. [CrossRef] [PubMed]

2. Alexander, F.; Eggert, S.; Wiest, J. A novel lab-on-a-chip platform for spheroid metabolism monitoring. Cytotechnology 2017, 70, 375-386. [CrossRef] [PubMed]

3. Xiao, S.; Coppeta, J.R.; Rogers, H.B.; Isenberg, B.C.; Zhu, J.; Olalekan, S.A.; McKinnon, K.E.; Dokic, D.; Rashedi, A.S.; Haisenleder, D.J.; et al. A microfluidic culture model of the human reproductive tract and 28-day menstrual cycle. Nat. Commun. 2017, 8, 14584. [CrossRef] [PubMed]

4. Mehling, M.; Tay, S. Microfluidic cell culture. Curr. Opin. Biotechnol. 2014, 25, 95-102. [CrossRef] [PubMed]

5. Hung, P.J.; Lee, P.J.; Sabounchi, P.; Lin, R.; Lee, L.P. Continuous Perfusion Microfluidic Cell Culture Array for High-Throughput Cell-Based Assays. Biotechnol. Bioeng. 2004, 89, 1-8. [CrossRef] [PubMed]

6. Gomez-Sjoberg, R.; Leyrat, A.A.; Pirone, D.M.; Chen, C.S.; Quake, S.R. Versatile, Fully Automated, Microfluidic Cell Culture System. Anal. Chem. 2007, 79, 8557-8563. [CrossRef] [PubMed]

7. Young, E.W.K.; Beebe, D.J. Fundamentals of microfluidic cell culture in controlled microenvironments. Lab Chip 2010, 39, 1036-1048. [CrossRef] [PubMed]

8. Wu, M.; Huang, S.; Lee, G. Microfluidic cell culture systems for drug research. Lab Chip 2010, 10, 939-956. [CrossRef] [PubMed]

9. Boyd-Moss, M.; Baratchi, S.; Di Venere, M.; Khoshmanesh, K. Self-contained microfluidic systems: A review. Lab Chip 2016, 17, 3177-3192. [CrossRef] [PubMed]

10. Huh, D.; Hamilton, G.A.; Ingber, D.E. From 3D cell culture to organs-on-chips. Trends Cell Biol. 2011, 21, 745-754. [CrossRef] [PubMed]

11. Zhang, B.; Kim, M.; Thorsen, T.; Wang, Z. A self-contained microfluidic cell culture system. Biomed. Microdevices 2009, 11, 1233. [CrossRef] [PubMed]

12. Futai, N.; Gu, W.; Song, J.W.; Takayama, S. Handheld recirculation system and customized media for microfluidic cell culture. Lab Chip 2006, 6, 149-154. [CrossRef] [PubMed]

13. Zhang, R.; Larsen, N.B. Stereolithographic hydrogel printing of 3D culture chips with biofunctionalized complex 3D perfusion networks. Lab Chip 2017, 17, 4273-4282. [CrossRef] [PubMed]

14. Raimes, W.; Rubi, M.; Super, A.; Marques, M.P.C.; Veraitch, F.; Szita, N. Transfection in perfused microfluidic cell culture devices: A case study. Process Biochem. 2017, 59, 297-302. [CrossRef] [PubMed]

15. Haefner, S.; Koerbitz, R.; Frank, P.; Elstner, M.; Richter, A. High Integration of Microfluidic Circuits Based on Hydrogel Valves for MEMS Control. Adv. Mater. Technol. 2018, 3, 1700108. [CrossRef]

16. Xu, L.; Lee, H.; Jetta, D.; Oh, K.W. Vacuum-driven power-free microfluidics utilizing the gas solubility or permeability of polydimethylsiloxane (PDMS). Lab Chip 2015, 15, 3962-3979. [CrossRef] [PubMed]

17. Ozasa, K.; Lee, J.; Song, S.; Hara, M.; Maeda, M. Gas/liquid sensing via chemotaxis of Euglena cells confined in an isolated micro-aquarium. Lab Chip 2013, 13, 4033-4039. [CrossRef] [PubMed]

18. Cook, C.A.; Liu, Y.; Lu, J.; Chen, N.; Fong, Y.; Tai, Y. Gas perfusable microfabricated membranes for high-density cell culture. In Proceedings of the 2017 IEEE 30th International Conference on Micro Electro Mechanical Systems (MEMS), Las Vegas, NV, USA, 22-26 January 2017. [CrossRef]

19. Lee, M.K.; Rich, M.H.; Baek, K.; Lee, J.; Kong, H. Bioinspired Tuning of Hydrogel Permeability-Rigidity Dependency for 3D Cell Culture. Sci. Rep. 2015, 5, 8948. [CrossRef] [PubMed]

20. Ozasa, K.; Lee, J.; Song, S. Cell multiplication and movement analysis of swimming euglena confined in a flow-isolated microaquarium. In Proceedings of the 18th International Conference on Miniaturized Systems for Chemistry and Life Sciences, San Antonio, TX, USA, 26-30 October 2014; pp. 497-499. 
21. Kamei, K.; Mashimo, Y.; Koyama, Y. 3D printing of soft lithography mold for rapid production of polydimethylsiloxane-based microfluidic devices for cell stimulation with concentration gradients. Biomed. Microdevices 2015, 17, 36. [CrossRef] [PubMed]

22. Podwin, A.; Dziuban, J.A. Modular 3D printed lab-on-a-chip bio-reactor for the biochemical energy cascade of microorganisms. J. Micromech. Microeng. 2017, 27, 104004. [CrossRef]

23. Zhang, H.; Cloud, A. The Permeability Characteristics of Silicone Rubber. In Proceedings of the Global Advances in Materials and Process Engineering, Coatings and Sealants Section, Dallas, TX, USA, 6-9 November 2006.

24. Barbier, J. A Study of Permeability to Gases. Mixtures of Natural Rubber and Other Elastomers. Rubber Chem. Technol. 1955, 28, 814-820. [CrossRef]

25. Van Amerongen, G.J. Influence of Structure of Elastomers on Their Permeability to Gases. Rubber Chem. Technol. 1951, 24, 109-131. [CrossRef]

26. Walczak, R.; Adamski, K.; Lizanets, D. Inkjet 3D printed check microvalve. J. Micromech. Microeng. 2017, $27,104004$. [CrossRef]

27. Adamski, K.; Kubicki, W.; Walczak, R. 3D printed electrophoretic lab-on-chip for DNA separation. Procedia Eng. 2016, 68, 1454-1457. [CrossRef]

28. Podwin, A.; Kubicki, W.; Dziuban, J.A. Study of the behavior of Euglena viridis, Euglena gracilis and Lepadella patella cultured in all-glass microaquarium. Biomed. Microdevices 2017, 19, 63. [CrossRef] [PubMed]

29. Lizanets, D.; Dziuban, J.A.; Walczak, R. Comparison of algorithms for detection and real-time tracking of living microorganisms in lab-on-a-chip devices. In Proceedings of the MIXDES-24th International Conference on Mixed Design of Integrated Circuits and Systems, Bydgoszcz, Poland, 22-24 June 2017.

30. Lizanets, D.; Walczak, R. Algorithms and approaches for processing an output signal from lab-on-a-chip devices in bioanalysis. In Proceedings of the 2016 XII International Conference on Perspective Technologies and Methods in MEMS Design (MEMSTECH), Lviv, Ukraine, 20-24 April 2016.

31. Merkel, T.C.; Bondar, V.I.; Nagai, K.; Freeman, B.D.; Pinnau, I. Gas sorption, Diffusion, and Permeation in Poly(dimethylosiloxane). J. Polym. Sci. Part B Polym. Phys. 2000, 38, 415-434. [CrossRef]

32. Lamberti, A.; Marasso, S.L.; Cocuzza, M. PDMS membranes with tunable gas permeability for microfluidic applications. RSC Adv. 2014, 4, 61415-61419. [CrossRef]

33. Kuo, A.C.M. Poly(dimethylosiloxane); Polymer Data Handbook; Oxford University Press, Inc.: Oxford, UK, 1999; pp. 411-435.

34. Solomon, E.; Berg, L.; Martin, D.; Villee, C. Biology; Multico: Warsaw, Poland, 2000.

35. Ozasa, K.; Lee, J.; Song, S.; Maeda, M. Transient Freezing Behavior in Photophobic Responses of Euglena gracilis Investigated in a Microfluidic Device. Plant Cell Physiol. 2014, 55, 1704-1712. [CrossRef] [PubMed]

36. Einicker-Lamas, M. Euglena gracilis as a model for the study of $\mathrm{Cu} 2+$ and $\mathrm{Zn} 2+$ toxicity and accumulation in eukaryotic cells. Environ. Pollut. 2002, 120, 779-786. [CrossRef]

37. Cramer, M.; Myers, J. Growth and Photosynthetic Characteristics of Euglena gracilis. Arch. Mikrobiol. 1952, 17, 384-402. [CrossRef]

(C) 2018 by the authors. Licensee MDPI, Basel, Switzerland. This article is an open access article distributed under the terms and conditions of the Creative Commons Attribution (CC BY) license (http:/ / creativecommons.org/licenses/by/4.0/). 